\title{
Variceal Banding
}

National Cancer Institute

\section{Source}

National Cancer Institute. Variceal Banding. NCI Thesaurus. Code C126289.

An endoscopic procedure in which an elastic ring is placed around an enlarged

esophageal vein to cut off the blood flow through the vein. It is used to prevent bleeding from esophageal varices. 